\title{
Ethical Dimensions of Bioethics Education with a Special Overview of the Situation in Serbia
}

\author{
Ruzica Petrovic ${ }^{1}$ \\ ${ }^{1}$ Faculty of Pedagogical Sciences, University of Kragujevac, Jagodina, Republic of Serbia \\ Correspondence: Ruzica Petrovic, Faculty of Pedagogical Sciences, University of Kragujevac, Jagodina, Republic \\ of Serbia. E-mail: prof.ruzica@gmail.com
}

Received: December 10, $2013 \quad$ Accepted: January 7, $2014 \quad$ Online Published: January 16, 2014
$\begin{aligned} & \text { doi:10.5539/res.v6n1p53 } \\ & \text { URL: http://dx.doi.org/10.5539/res.v6n1p53 }\end{aligned}$

\begin{abstract}
The subject of this study is to explore bioethics as a multidimensional scientific field that within its content reflects issues imposed by the highly developed biotechnological era. In this context, the topic of bioethics education and its moral implications on the development of ethical awareness of students was selected. The aim of this contribution is to highlight the theoretical and practical importance of the study of bioethics as a teaching discipline in the system of institutional education. The author's theoretical starting point allows insight into the contents of bioethics research and the status of bioethics education in the wider socio-historical discourse, with a special overview of the situation in Serbia.
\end{abstract}

Keywords: bioethics, bioethics education, science, ethics, values

\section{Introduction}

The author starts with the fact that the introduction of Bioethics education in the system of academic education stems from the development of bioethics as a new, pluralistic approach to the research of value connotations of biotechnological use of scientific knowledge. High cognitive achievements of scientific endeavours in the research of biological and genetic structure of human beings and the potential of their technological use highlights the need to rethink their moral justification. This paper brings into a complementary relationship bioethics as an interdisciplinary orientation that based on scientific, philosophical, theological and humanistic skills develops ethical discourse on moral dilemmas posed by professional and life practice and bioethics as a school-based subject that theoretically and methodologically conforms those skills to parameters of pedagogical work with the view to raise the level of ethical reflection of students on issues related to bioethics. The author assumes that the bioethics educational program naturally builds onto the ethical skills, and that knowledge of ethical theories and teachings on the nature of good and evil can be a good basis for improving the quality of ethical reflection on issues that in scientific and technological research and application have morally multifaceted character. These are the issues regarding the ethics of life and human rights, such as the right to life, the right to take a life at the embryonic stage (abortion) or before its natural end (euthanasia), the right to assisted human reproduction (in vitro fertilization), to improve human species including eugenics program supported by genetic engineering, environmental ethics, the issue of organ transplantation, cloning, the use of animals for experimental purposes and the like. This paper emphasizes two goals of Bioethics education: cognitive, which includes the adoption of scientific-civilizational results and their use in life practice and educational-moral, which includes the promotion of pluralistic values, judgments and beliefs as a basis for argumentative expression of individual freedom to make moral decisions. Finally, the author provides an overview of bioethical education in Serbia

\section{Origin and Definition of Bioethics}

In order to realize the role and the importance of the development of bioethics and its academic study within the system of education, it is important to examine its nature, the causes of its origin and its orientation perspective from the horizon of philosophical discourse. Bioethical awareness, as a way of respect for life, is based on a deep primal connection of man with nature and all living beings. It emerged much earlier than it has been constituted as a special interdisciplinary field of research. Initially, it represented the deepest reflective and experiential relation of man to the entire living world and the concern to preserve it (Taylor, 1986). It was not burdened with the experience of the destructive relationship of man to nature, or artificial raising of the limits of human 
biological powers that came with the epoch of scientific discoveries and technological shaping of the world and the man. Hence, bioethical awareness of pre-industrial civilizations represents the expression of organic unity of man, nature and the entire living world. Rich and varied forms of mythological, religious and artistic creation testify to this. The first industrial-technological development led to an imbalance between man and nature, when the nature became the object of man's "submission", slowly losing its mysterious character. Thus, contemporary bioethics had arisen from a negative position as a critical awareness of the complex moral situation of the current era.

The contemporary origin of bioethics began as a social movement, which involved the establishment of Bioethics Committee in 1962 in Seattle (Seattle Artificial Kidney Center) (Note 1). The Board of Trustees of this Committee, comprised of 19 members, included only two doctors of medicine, which sent the message that moral dilemmas in medicine, formed by the scientific and technological development, could not be considered as strictly professional, and that their resolution required a multidimensional approach.

The origin of bioethics is related to the "new civilization situation" in which faith and confidence in science as the undisputed criterion for the constitution of socio-cultural contexts of the human shaping of the entire life are shaken. It has kept the place of a powerful force, but not the confidence in the infallibility of creation and design of human existence without participation of other spiritual forces. In seeking support in consciousness that will meet the challenges and needs of the new epoch, bioethics has developed as a complex problem domain open to scientific, professional, philosophical, legal, theological debate with questions posed by the new time. Its appearance is directly related to new scientific discoveries in the field of genetics, biomedicine, bioengineering and capabilities that new technologies provide in their application, as well as the position in which the nature and the entire living world finds itself (Lindsay, 2008). The contemporary situation raised, first of all, questions of moral justification of a new mode of action on man which shifted the natural boundaries of formation and shaping of life.

Starting from the etymological origin of the word, bioethics can be defined as the ethics of life (Greek: bios = life, etika = ethics). Its origin and use (Note 2) are linked to the biochemist Van Rensselaer Potter, who defined bioethics as the science of balance between man and nature and the "bridge towards the future of humanity". Its establishment as the "new medical ethics" is linked to the name of fetal physiologist André Hellegers, founder of the Institute for Human Reproduction (1971). Scientific and philosophical foundation of bioethics and its academic study is credited with Albert R. Jonsen, who was the first to teach bioethics at U.S. universities in 1980 Taking into account the definitions of the world bioethicists (Callahan, Clouser, Engelhardt, Pellegrino, \& Hellegers, et al.), he gave bioethics the character of a scientific domain, which integrated biomedical knowledge relating to borderline human situations (Johnsen, 1998) (Note 3). A very established definition of bioethics was given in the first edition of the Encyclopedia of Bioethics (1978), where it was defined as "the study of human conduct in the domain of life and health care science if the conduct was examined in the light of moral values and principles" (Segota, 1999, p. 11). This definition corresponds to the first phase of the development of bioethics when it establishes a direct moral reflection on issues posed by the new biomedical practice, in order to define and establish the principles of action in particular situations. Further development of bioethics began to critically review moral values, question the accepted paradigms, discussing their feasibility and ethical foundation. This methodological shift towards higher ethical level of reasoning and expansion of the bioethical domain from the biomedical to the global domain of life, found its theoretical expression in modification of the definition of bioethics in the second edition of Encyclopedia of Bioethics (1995) according to which bioethical approach includes "a variety of ethical methodologies in an interdisciplinary environment". In growing of bioethics from moral thinking to the level of ethical discourse, it stepped out from the limited field of medical and normative ethics, and thus opened new planetary premises to the ethics of life. In building a methodological basis, it found its support in the unity of scientific interdisciplinarity, ethical pluralism, and philosophical heritage.

\section{Bioethics Education}

From the time when bioethics had received its academic place in the system of education in 1970, the determination of its pedagogical and value norms does not seem to cease. Given its very wide range of research, the process of its theoretical-substantive and methodological establishment still remains open. Its introduction into the teaching process began in medical schools in the United States, as they were the first to express the need to submit to the moral assessment of specific cases resulting in high tech medical conditions, for the proper resolution of which medical professionals were not enough. Along with medical schools, bioethical issues were incorporated in the curriculum of natural sciences, especially biology (Leder, 1995). However, such a project did not prove successful enough due to lack of necessary tendency of natural sciences towards the development of 
knowledge and skills for ethical reasoning and comparison of moral attitudes to scientific evidence. In further inclusion of bioethics in the system of education, its study began in philosophical and theological schools, especially in the departments of philosophy and religion within the teaching of ethics. Thus, it began to form a multidisciplinary foundation. In designing the study program, bioethics has gone through a number of developmental stages in order to, after many modifications enter into a phase of standardization.

In the methodological elaboration of this chapter, the author starts from the basic contents, objectives and methods of bioethics education based on American concepts, which represent the first academic experience in the study of bioethics discipline.

American understanding of bioethics is based on its differentiation as medical ethics pervaded with social and human sciences (Pellegrino, 1989). The following proposals are based on that important determinant: a) design of teaching content should take into account the fact that students come to college with an already established ethical knowledge and moral attitudes, and that in this sense, ethics and bioethics should not be in a function of building their views and value orientations, but in the function of their personal examination of previously acquired knowledge and principles; b) the study programs of bioethics should be designed to provide comprehensive knowledge of biotechnological possibilities of action on man and to encourage the development of moral sensitivity of students to the scientific results the technological application of which has a controversial character (Burns, 1980).

By analysing the teaching content of bioethics in medical schools in the United States, some areas that are incorporated in it can be pointed out: a) the historical part, which includes the development of medical ethics, ethics and bioethics; b) the theoretical foundation that is based on comparative knowledge of religion, sociology, culture, computer science; c) methodological framework that allows ethical analysis and practical resolution of concrete problems in the profession (Thorton \& Callahan, 1993).

The introduction of bioethics at U.S. universities has been accompanied by certain shortcomings that have emerged through the difficulties in achieving the set objectives. If one takes into account the fact that the disciplinary establishment of bioethics began in the early seventies of the last century, then it is expected that one of the shortcomings was of theoretical nature and referred to the lack of relevant genuine literature on bioethical phenomena that required moral problematization, and which referred to: Nazi eugenics program, experiments on prisoners, legalization of abortion, euthanasia, organ transplants, and more. Another difficulty was of methodological character and included the approach to the study of ethics, which was mainly restricted to the study of texts in moral philosophy, without analysis of specific case studies. The focus of attention of students on precisely this problem resulted in their demand for introduction of new methods that would enable them to not only identify and describe certain cases of professional practice, but also prepare them for their practical resolution using ethical knowledge. Jonsen, who for the purpose of its resolution wrote a book called Clinical Ethics, dealt with this issue very seriously.

Further development of bioethics in the United States was marked by the differentiation of two trends, created as a result of biotechnological development, one of which started perceiving bioethics in a broader sense and included general questions on ethics of life and nature, while the other was focused on more specific issues of moral dilemmas. These trends can be noted in the Encyclopedia of Bioethics (Robert Veatch), which provided the basic guidelines in designing curriculum in bioethics and significantly enriched the study content. After a comprehensive analysis of study programs of bioethics education at American universities, in 1980 the researchers of the Hastings Center made an assessment that it is difficult to come up with a unique teaching content, so they only gave suggestions for its conception in the framework of a research project.

\section{Bioethics Education in Serbia}

This chapter presents the development of bioethics in Serbia, its scientific research and academic study. In the methodological procedure, the author starts with the presentation and analysis of the role of national bodies and associations for bioethics, the importance of scientific activities within research centers, contribution of the latest scientific research studies of bioethical phenomena and in the final consideration deals with the concept of bioethics curricula.

The need for bioethics, bioethics education and research, in Serbia as well as in the rest of the world was first recognized in medicine, and then in other natural sciences and socio-humanitarian domains. Within the scope of activities of the National Committee for Bioethics in 2006, at the Serbian Academy of Sciences and Arts a conference called Bioethics in Serbia and Abroad was organized, with the mission to promote the moral dimension of multidisciplinary research of life in all its aspects and to foster bioethics education. Bioethics Society of Serbia within the framework of its activities organized a scientific conference Bioethics Education - 
Sharing Various Experiences, on January 1, 2010, and from 4 to 7 November 2010: the 6th Bioethics Forum for South Eastern Europe: Bioethics - Medicine - Politics was held. Noteworthy is the scientific conference held in 2012 at the Institute for Philosophy and Social Theory at the Center for the Study of Bioethics, on the topic (New) Perspectives on Bioethics.

Thanks to the research efforts within the framework of scientific projects as well as the translation activities, in recent years there has been a significant number of proceedings and books, which represents the beginning of the formation of bibliographic material on bioethics. Among the first in our country who began to deal with bioethics was the ethicist, Professor Jovan Babic, with the two papers published back in the nineties: Assisted Human Reproduction in Theory, No. 4, 1992 and Moral Dimension of Reproductive Rights, in the Proceedings Reform of the Family Law, Faculty of Law, Belgrade, 1996. Both studies deal with theoretical analysis of bioengineering as a new practice that when applied to people brings new dilemmas. The author notes that the new practices violate the existing discursive situation and that theoretical redefinition of established ethical concepts, subjection to moral assessment of new procedures and determination of their ethical meaning is necessary. In this context, a request for reconsideration of moral justification of medical interventions related to: in-vitro fertilization, surrogate motherhood and donation of genetic reproductive material is introduced. The author advocates the establishment of a demarcation line, which would not forbid anything that should be allowed and not allow anything that should be forbidden (Babic, 2012, pp. 15-68). A significant contribution to the research of the topic of reproduction can be attributed to the study conducted by Drezgic R. called Reproductive Technologies and Feminist Bioethics, which in exploring social consequences and ethical implications of the use of reproductive technologies, comes to the conclusion that traditional concepts support critical discourse in which assisted forms of maternity are deemed "unnatural", while on the contrary alternative practices that contribute to a new understanding of bioethical phenomena of motherhood, parenting, family are being formed. In her opinion the new reproductive technologies have contributed to the conceptual transformation of the category of "natural" (Drezgic, 2012, pp. 68-87). The subject of reproduction is also enriched by the contribution of Jovanovic, D. The Welfare State, Population Policy and Bioethics Care in Serbia, which explores the importance of initiative to increase the population of Serbia in the form of media presentation of pregnant women, birth, motherhood, family life, with the aim of raising awareness about the decline in birth rate. Her view implies "a feminist ethics of care" as a kind of participatory approach to resolving this issue (Jovanovic, 2012, pp. 87-105).

Within the bioethical topic there are many scientific contributions that deal with the phenomenon of "enhancement". Gligorov N. gave a significant contribution to the study of this question, in her study called Seeking More than Health. In the scope of discussion about enhancement, she considers the views of Fukuyama and Sandez who advocate limiting medical intervention on sick people. By differentiating between the concepts of treatment and enhancement she sets forth a number of questions, such as: can psychophysical substances be used for enhancement and whether the terms "disability" and "normality" can be used as criteria for evaluating the permissibility of medical enhancement (Gligorov, 2012, pp. 105-122). Question of enhancement leads to a different angle of approach in the text Moral framework of cognitive enhancement. Its author (Rakic, 2012) argues that in addition to two aspects of enhancement: cognitive enhancement as a moral duty (Savulescu) and moral enhancement as a precursor of cognitive enhancement (Harris), there is also a third more acceptable aspect, which assumes that cognitive enhancement is morally permissible only if it leads to moral enhancement.

Very valuable scientific research was developed on the issue of rare diseases. Such a contribution can be found in the text by Krajinovic (2012, pp. 231-253) called Ethical and Social Aspects Related to Rare Diseases, which addresses the problems faced by patients and their family members due to lack of legal regulations, unavailability of appropriate diagnostic procedures, information about the disease, lack of adequate health care, discrimination in access to new medical technologies, marginalization in social relations and in health care. She brings forth the fact that in Serbia, citizens' associations are the strongest drivers of the public in solving the problems of patients and drivers of change in addressing regulatory issues related to prevention, treatment and rehabilitation. It was their initiatives and activities that greatly contributed to the current amendments to the Law on health care that allowed those who are suffering from rare diseases to gain a category of particularly vulnerable social group. This applies to organ transplant programs for children who are now included in the program of required state financial aid thanks to new changes.

Noteworthy is the contribution of studies which from the aspect of legal, biomedical, anthropological, and other fields discuss issues such as: the right to life, the right to a dignified death, (Besirevic), genetic modification of plants and animals (Kaludjerovic), ecofeminism (Djuric), ethics of the environment (Petrovic) and many others. 
A significant effort in bringing the relevant world literature on this subject closer to our professional and general public is represented by the Proceedings of translated texts by known bioethicists, titled Bioethics, published by the Official Gazette and the Institute for Philosophy and Social Theory, in 2012. This collection of 695 pages made the material on following topics available in Serbian language: abortion, euthanasia, cloning, human enhancement, rare diseases, experiments on stem cells, diagnostics in prenatal period; which were written by: Judith Jarvis Thomson, Mary Anne Warren, John M. Finnis, Bonnie Steinbock, Don Marquis, Rayna Rapp, Nicholas Agar, Julian Savulescu, John Harris, Gregory Pence, Anna Smajdor, Frances M. Kamm, Peter Singer, James Rachels, and many others.

Bioethics has assumed institutional form and became the subject of study according to the situation that necessitated engaged awareness about the issues regarding the ethics of life. In recent years, this interdisciplinary field in Serbia began to occupy an important place in the academic community and medical facilities. Thus, in 2003 at the initiative of the Serbian Academy of Sciences and Arts The National Committee for Bioethics was established, in charge of addressing ethical issues in scientific research. It was comprised of 11 members including: five doctors of medicine, four biologists, an anthropologist and an agronomy geneticist. This Committee became a member of the International Bioethics Committee of UNESCO, based in Paris and a member of the Association of Bioethics Committees of the Council of Europe, based in Strasbourg. The National Bioethics Committee was also formed at the Faculty of Medicine in Nis, where the study program Ethics of scientific research is taught at the doctoral studies. At the Medical Faculty in Belgrade in 2008, The Bioethics Society of Serbia was established, which brought together scholars and researchers from different subject areas with the intention to integrate the knowledge of philosophy, ethics, law, sociology, medicine, theology and other scientific and professional domains.

In the system of academic education bioethics is studied at the Faculty of Medicine, University of Belgrade, Faculty of Medicine, University of Nis, Faculty of Philosophy, University of Novi Sad, Faculty of Philosophy, University of Belgrade, Faculty of Law, University of Belgrade, Faculty of Education, University of Kragujevac. The Institute for Philosophy and Social Theory formed in 2012 The Center for the Study of Bioethics as an independent scientific research unit in order to initiate scientific debates and expert discussions on bioethical issues. Within the Center, a research subproject Bioethical Aspects: Morally Acceptable within the Biotechnologically and Socially Possible, was initiated as part of the project Rare Diseases: Molecular Pathophysiology, Diagnostic and Therapeutic Modalities, and Social, Ethical, and Legal Aspects (Project of the Ministry of Science and Technology of the Republic of Serbia). At the Faculty of Medicine in Nis, the following project was launched: Building Bioethics Master Program in Serbia.

Establishment of bioethics as a teaching discipline and its academic study in Serbia included the design of main objectives, contents and methods. Taking into account international experience, as well as specific social and educational requirements and conditions in Serbia, basic structural elements of teaching bioethics were designed.

Given that the main objective of bioethics education consists of raising awareness about the biotechnological spirit of modern civilization (Burns, 1980; Carson, 1980), preparation of contemporary man for dealing with moral issues posed by the new social practice and training for their resolution, its implementation began by setting the following tasks:

1. Acquisition of knowledge about the scope of scientific knowledge and the impact of its technological application on the entire culture - civilization order.

2. Training for ethical reflection on the issues of the future and the meaning of life.

3. Learning skills of substantiated argument in debates and discussions about the delicate moral issues.

4. Developing evaluative attitudes and orientations and strengthening of the autonomous will for independent decisions in specific professional or living conditions.

5. Encouraging development of moral sensitivity, feeling of moral duty and personal responsibility.

6. Training for the analysis of value connotations of personal attitudes, in order to be able to test their validity and viability in concrete situations (Pellegrino, 1989).

The content should conform to the set objectives and tasks, which could include within the study program a theoretical study of bioethical issues that involve:

1. The history of bioethics and the reasons for its formation. Theoretical and methodological foundations of ethical analysis of bioethical issues. Basic ethical and bioethical concepts, ethical theories and axiological orientations (Radinkovic, Drezgic, \& Krstic, 2012). The key bioethical issues such as: new 
approaches to the phenomenon of birth, life and death, assisted reproduction, human genetics, human rights, human trafficking, abuse of human organs, genetic engineering, the right to genetic enhancement of the human species, the use of animals for experimental purposes, environmental conservation, environmental ethics, and so on.

2. Theoretical adoption and understanding of ethical and bioethical knowledge and practical resolution of moral dilemmas that raise specific bioethical issues, requires the application of appropriate methodology.

In accordance with the set tasks, objectives and contents of bioethics education the methodology should include:

1. Implementation of pluralistic approach that involves exploring the relationship of bioethics and other scientific disciplines and domains, especially ethics, genetics, philosophy, law and theology.

2. Introduction to bioethical issues through the presentation of more than just one system of thought.

3. Development of tolerance to criticism and disagreement with opposing views.

4. Giving freedom to object to certain views and attitudes.

5. Presentation of different theories, recognizing the best ones and willingness to deviate from originally approved ones if the comparison shows their weaknesses.

6. Not imposing a point of view. Promotion of more approaches and possibilities, affirmation of freedom of choice and action.

7. Inclusion in bioethical research suited for a certain profession for which students are being educated and making the choice of appropriate subjects.

8. The basic form of teaching, through which students can systematically be introduced to the fundamental bioethical concepts, attitudes and learning is lecture. It provides the ability to define problems, interpret ethical subjects, acquire knowledge, develop awareness of the complexity of bioethical issues, learn about the solutions from the rich literature provided by bioethicists of different ethical orientations, stimulate awareness about the responsibility for reached conclusions and decisions, and encourage moral imagination and empathy.

9. The best form of complement to lectures are seminar papers, which through the form of debates, discussions, interviews, research, offer students the opportunity to develop critical and analytical approach, demonstrate willingness for accountable thinking and reasoned debate, express willing sensitivity in recognizing moral dilemmas and in individual search for their solutions. Given that these are the issues with complex and controversial nature for which there are many ambiguous definitions and possible solutions, it is important that the teacher searches for best answers along with students. Such an approach requires careful listening to other people's opinions and critical examination of one's own, in order to avoid mistakes in reaching the final conclusions and decisions, that one is responsible for. One of the objectives in implementation of this methodology is the "formation of character" (Lickon, 1996) according to ethical paradigm that includes the most important moral values of humane relations among people.

This brief overview of the development path of bioethics in Serbia shows a portion of scientific, research, teaching and translation activities conducted within the professional, scientific and academic institutions over the past ten years.

\section{Conclusion}

The development of bioethics was conducted in two phases. The first involved direct moral reflection on issues imposed by the new biomedical situation, in order to define and establish the principles of action in particular situations. The second phase was based on critical examination of moral values, discussing their merits and ethical considerations of moral phenomena. Although it was created as a moral challenge to issues that, above all, were raised by modern medical practice accompanied by scientific knowledge and its technological application, it has now risen to the paradigm that integrates disputable issues in the domain of natural sciences, ecology, human rights, with the aim to design a new concept of the human world.

The inclusion of philosophers, lawyers, theologians, ethicists, educators, ecologists, anthropologists in addressing sensitive moral issues that emerged from the domain of classical medical ethics, has created interdisciplinary roads of bioethical concept of research and education. Thus, bioethics has, on the one hand, found support in ethical categorical apparatus, developed ethical theories and argumentative mechanisms, and on 
the other hand, established a higher level of responsibility in raising the issues that go beyond the framework of philosophical ethics and refer to the entire life, the conditions of its maintenance and global orientation. By focusing in its research not only on "moral but also on general civilization aspects of life", bioethics is proving to be a spiritual sign of new times in which the conflict of moral and civilizational dilemmas has grown.

\section{References}

Beauchamp, T. L., \& Childress, J. F. (2001). Principles of Biomedical Ethics. New York. Oxford University Press.

Burns, C. R. (1980). Liberating Medical Minds: Can Historians Help? The Role of the Humanities in Medical Education (pp. 8-21). Virginia, Eastern Virginia Medical School and Old Dominion University.

Carson, R. A. (1980). Religion and Medical Education. The Role of the Humanities in Medical Education (pp. 8-21). Virginia, Eastern Virginia Medical School and Old Dominion University.

Covic, A. (2004). Ethics and Bioethics. Zagreb, Pergamena.

Drezgic, R. (2012). Reproductive Technologies and Feminist Bioethics. Horizons of Bioethics-morality in an age of technical reproduction of life. Belgrade, University of Belgrade, Institute for Philosophy and Social Theory

Gligorov, N. (2012). Seeking More than Health. Horizons of Bioethics-morality in an age of technical reproduction of life. Belgrade, University of Belgrade, Institute for Philosophy and Social Theory.

Gosic, N. (2005). Bioethical education. Zagreb, Pergamena.

Jonsen, A. R. (1998a). Medical Ethics Teaching. Academic Medicine. Journal of the Association of the American Medical Colleges, 12, 717-724.

Jonsen, A. R. (1998b). The Birth of Bioethics. New York: Oxford University Press.

Jonsen, R. A., \& Singler, M. (1992). Clinical Ethics. New York.

Jovanovic, D. (2012). The Welfare State, Population Policy and Bioethics Care in Serbia. Horizons of Bioethics-morality in an age of technical reproduction of life. Belgrade, University of Belgrade, Institute for Philosophy and Social Theory.

Krajinovic, D. (2012). Ethical and Social Aspects Related to Rare Diseases. Horizons of Bioethics-morality in an age of technical reproduction of life. Belgrade, University of Belgrade, Institute for Philosophy and Social Theory.

Leder, D. (1995). Bioethics Education: Other Health Profession. Encyclopedia of Bioethics. New York.

Lickon, T. (1996). Eleven Principles of Effective Character Education. Journal of Moral Education, 1, 94-101.

Lindsay, A. R. (2008). Future Bioethics: Overcoming Taboos, Myths, and Dogmas. Prometheus Books.

Pellegrino, D. E. (1989). Teaching Medical Ethics: Some Persistent Questions and Some Responses. Academic Medicine. Journal of the Association of the American Medical Colleges, 64, 701-705. http://dx.doi.org/10.1097/00001888-198912000-00002

Radinkovic, Z., Drezgic, R., \& Krstic, P. (Eds.) (2012). Horizons of Bioethics-morality in an age of technical reproduction of life. Belgrade, University of Belgrade, Institute for Philosophy and Social Theory.

Rakic, V., Mladenovic, I., \& Drezgic, R. (Eds.) (2012). Bioethics. Belgrade, Sluzbeni glasnik.

Reich, W. T. (Eds.) (1995). Encyclopedia of Bioethics. New York: Macmillan-Free Press.

Segota, I. (1999). Bioethical volumes (Vol. 1, p. 11). Rijeka. Faculty of Medicine.

Taylor, W. P. (1986). Respect for Nature: A Theory of Environmental Ethics. Princeton University Press.

\section{Notes}

Note 1. "Artificial Kidney Center" was established in Seattle as Belding Scribner had perfected the dialysis machine. Out of 15,000 patients, only a limited number of them could be subjected to dialysis, which raised the question of the criteria by which selection should be made. Since the decision on the selection of those who would be connected to the dialysis machine meant the matter of life and death, The Board of Trustees of "The Admissions and Policy Committee of the Seattle Artificial Kidney Center" was formed and was entrusted with 
the role of choice. Its professional composition was heterogeneous. Out of 19 members, only two members were doctors of medicine, while others covered other areas of expertise.

Note 2. Van Rensselaer Potter was the first to use the word bioethics in 1971 in the title of his book Bioethics: Bridge to the Future (Prentice-Hall. Englewood Cliffs).

Note 3. Cf. Beauchamp, T. L. \& Childress, J. F. (2001). Principles of Biomedical Ethics. New York. Oxford University Press.

\section{Copyrights}

Copyright for this article is retained by the author(s), with first publication rights granted to the journal.

This is an open-access article distributed under the terms and conditions of the Creative Commons Attribution license (http://creativecommons.org/licenses/by/3.0/). 